l'expérience humaine; quand je professais, il y a longtemps, que l'hydrogine était plus près des métaux que de toute autre classe de corps; j'émettais des opinions que les découvertes actuelles viennent confirmer et que je n'ai point à modifier aujourd'hui." 1

One of the replies to my working hypothesis was that the various chemical elements probably existed in different proportions in the different stars, and that it so happened that in Vega and Sirius one of them, hydrogen, existed practically alone.

In I 878 I went furtber, and showed that thousands of solar phenomena which had been carefully recorded during the previous years could only be explained by assuming that the changes in the various intensities of lines in the line spectrum itself indicated successive dissociations. I pictured the effect of furnaces of different temperatures, and I wrote as follows: ${ }^{2}$

"It is abundantly clear that if the so-called elements, or, more properly speaking, their finest atoms-those that give us line spectra-are really compounds, the compounds must have been formed at a very high temperature. It is easy to imagine that there may be no superior limit to temperature, and therefore no superior limit beyond which such combinations are possible, because the atoms which have the power of combining together at these transcendental stages of heat do not exist as such, or rather they exist combined with other atoms, like or unlike, at all lower temperatures. Hence association will be a combination of more complex molecules as temperature is reduced, and of dissociation, therefore, with increased temperature, there may be no end."

In 1878 I went back to the study of the changes in the line spectra in relation to the changes observed when known compounds were dissociated, and after discussing certain objections I submitted the conclusion that the known facts with regard to the changes in line spectra " are easily grouped together, and a perfect continuity of phenomena established on the hypothesis of successive dissociations analogous to those observed in the cases of undoubted compounds." 3

It is thus seen that the conclusions to which my spectroscopic work up to the year 1880 had led me, tended in exactly the same direction as that indicated by more purely chemical inquiries thus referred to by Berthelot in that year:-

"L'étude approfondie des propriétés physiques et chimiques des masses élémentaires, qui constituent nos corps simples actuels, tend chaques jour d'avantage à les assimiler, non à des atomes indivisibles, homogènes et susceptibles d'eprouver seulement des mouvements d'ensemble, ... . il est difficile d'imaginer un mot et une notion plus contraires à l'observation; mais à des édifices fort complexes, doués d'une architecture spécifique et animés des mouvements intestins très variés." 4

NORMAN LOCKYER.

DRIFT-BOTTLES AND SURFACE CURRENTS. $T$ HE rather anomalous results arrived at by some or bottle method of ascertaining the surface movements of the waters of the sea, make the discussion of a large number of these observations of special value at the present time. Such is to be found in Dr. Schott's able and elaborate paper on the "Flaschenposten" in the possession of the Deutsche Seewarte, published a short time ago in the Archiv.

After an historical introduction, in which it appears that the earliest recorded current observation of this kind is

1 "Chemistry of the Sun," p. 205.

2 Proc. Roy. Soc., vol. xxvili. p. I69. See also "Chemistry of the Sun," chap. xviii.

3 Roy. Soc. Proc., vol. xxviii. p. 179 .

4 Comptes rendus, r880, vol. xc. p. I5I2.

NO. I 536 , VOL. 59] about a century old, Dr. Schott describes the material at his disposal, which consisted of about 600 records found up to the end of the year 1896 . One important point here brought out is that no consistent difference can be observed in either direction or rate of drift between empty floats and floats loaded so as to ensure complete immersion.

In arranging the records obtained from each of the great oceans, the first place is, of course, given to the North Atlantic, which includes no less than 452 , or 70 per cent. of the whole. The North Atlantic reçords are subdivided into six sections-those from floats set adrift in the North Sea and the English Channel; in the west wind region north of $30^{\circ} \mathrm{N}$. lat.; in the north-east trade wind region; those in the south-east trade wind region which were recovered beyond its northern limit; those in the region of south-west monsoons, and in the Mediterranean. The charts appended to the paper, of which we reproduce a specimen, contain only a selected number of the drift-tracks dealt with; full details are given in tabular form. In the cise of the other oceans, the whole of the observations are represented; the South Atlantic and the Pacific are each treated as a whole, while the Indian Ocean is divided into the monsoon region, the south-east trade belt, and the "brave west winds."

Summing up in a final paragraph, Dr. Schott concludes that on the whole the method of drift-bottles yields valuable information both as to the direction and speed of surface currents. From this, however, the monsoon regions are expressly excepted : the number of bottles found within the period of one monsoon is necessarily small, and the few found give unsatisfactory results. As specially favourable instances, Dr. Schott quotes his results in the Bay of Biscay, disproving the existence of Rennell's current (no reference is made, by the way, to the work of Hautreux); in the West Indies, where the concentration of immense quantities of surface-water from the coast of Portugal and from the South Atlantic is clearly shown ; in the west wind drift of the southern hemisphere, and in the splitting of the southern equatorial current off the east coast of Madagascar. In this connection special stress is rightly laid on the record of two bottles, one loaded with sand and the other not, thrown overboard from the s.s. Paranagua in $13^{\circ} 49^{\circ}$ N. lat. and $25^{\circ} 34^{\prime} \mathrm{W}$. long., and picked up together on the island of Santiago (Cape Verd Island) after a journey of I 31 miles in twenty-one days, the direction being north-east by east with a weak current (whose existence was shown by independent observations recorded in ships' logs), and asainst the wind blowing at the time. In estimating the speed of current, the float method is found to be much less valuable, inasmuch as we can rarely be certain that the float is picked up immediateiy after it has reached the spot where it is found. Reasonably accurate estimates can only be looked for where a number of floats gives approximately the same result.

The justness of Dr. Schott's conclusions, so far as they go, seems to admit of little doubt, but we could have wished that his final statement of them, which will probably be much more widely read than the detailed discussion in the body of the memoir, had been expressed in a more guarded manner, and that to it he had added a note of warning, pointing out not only the extremely limited nature of the information afforded by the method, but the great risk of misinterpreting its results. Taking first the question of direction of surface currents : on the whole, the surface currents in perfectly open sea, clear of all land influences, follow the direction of the wind, and the float or bottle naturally takes the course common to both. Near land, the direction of the surface current is determined by three factors : first, and most important, the form of the coast line ; second, the prevailing wind; and third, a gravity factor, due to 
differences of level caused by off- and on-shore winds, inequalities of density, \&c. In this second case the current may, and often does, move in a direction forming a considerable angle with the wind; and the float may in most cases follow the current. That it does so in certain cases Dr. Schott has shown; but nearly every paper on this subject contains "erratics," and this is no exception. Several records are distinctly unsatisfactory; the most flagrant case is, perhaps, that of two identical floats started together in $1^{\circ} 44^{\prime} \mathrm{N}$. lat. and $27^{\circ} 16^{\prime} \mathrm{W}$. long., one of which was found on the coast of Nicaragua, and the other on the coast of Sierra Leone. Compare this with Mr. Russell's results on the east coast of Australia. "In view of the well-known southerly current on this coast, it is remarkable that so few of the
With regard to deductions as to the speed of a current based on records from floats, we are almost inclined to go further than Dr. Schott, and to regard such as practically valueless. The whole tendency of recent investigation has been to show that steady forward movement of surface water only occurs when there is a distinct "head" of water strongly controlled by the shape of the land; the best examples being the north and south currents moving polewards on the eastern sides of the great land masses. These currents come to an end as soon as they get clear of the land, and their waters are distributed by "drift" currents controlled primarily by the prevailing winds, but subject to continual variation, according to the relative amounts of denser and lighter water supplied by the true currents. But the movements of the drift currents

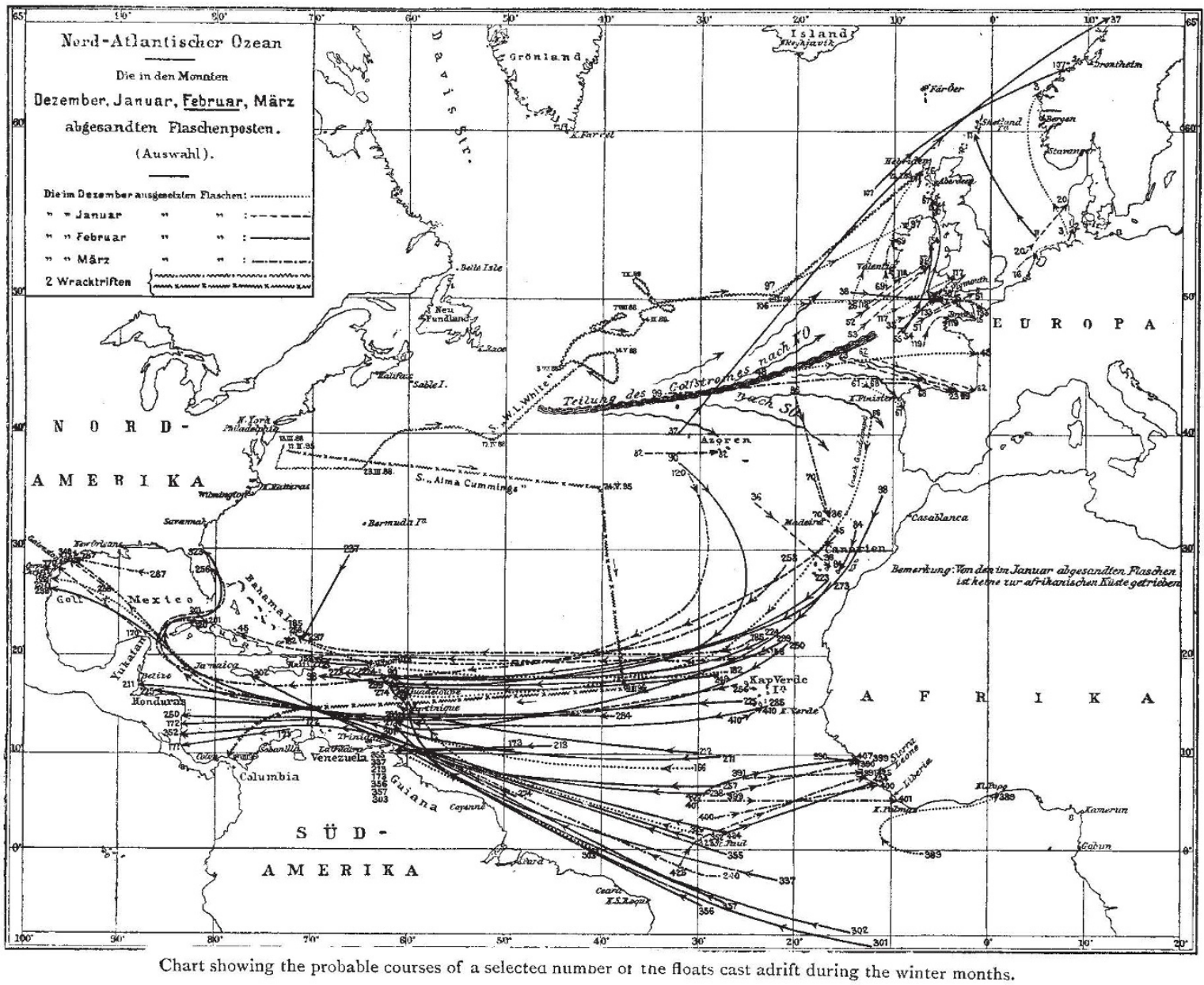

papers found seem to go with it, and that the majority of the papers found go against the current." Evidently great caution is necessary in applying the method. What seems most likely is that the relation of the movement of the float to that of the wind and of the surface water is really a function of the strength of the wind and the sea disturbance, and of the density of the water. A float may make headway with a current against a light wind; but if it meets with a cyclone, it, and perhaps a skin of water with it, may be removed from the surface of the current, a merely local disturbance transferring it to another member of the oceanic circulation: yet the "record" of this float would show the two currents as a continuous stream.

NO. I 536 , VOL. 59] are irregular in the extreme; the water goes backwards and forwards, the horizontal course of any particle of water, perhaps, resembling that of a particle of the air in the winds which drive it. The track of the Fram across the Polar Sea is probably a generalised form of such a course. In effect, there is no "river in the ocean," and we are not in general justified in joining the beginning and end of the course of a float by a continuous line. Under these circumstances, one is inclined to suspect that the wind has a considerable share in the high average velocities sometimes obtained for surface drifts from float observations.

Dr. Schott says little or nothing about the precise limitations which are to be observed in the interpretation of the float records, and it seems a pity that here 
again there is no note of warning. Assuming, for the moment, that floats give a trustworthy record of the movemerst of the surface water in which they are immersed, they give little information about the real motion of any body of water in their course. A single example must suffice to illustrate this. Set a float adrift in the Gulf of Mexico, and it is found in the Shetland Islands ; we cannot conclude that water has come from the Gulf of Mexico to the Shetlands-the current which brought the float to the banks of Newfoundland may have there become an under-current, and the float cannot follow it ; it remains on the surface, and is borne eastward by water which may have come from Davis Strait or Denmark Strait, where no floats are set adrift. No doubt the fact that the float took the course it did is interesting, and with sufficient knowledge of the mechanism, obtained from other sources, it may be of great value ; but even in a simple case, like that quoted, the greatest caution must be exercised, and the uncertainty becomes still greater in channels and enclosed seas.

It seems fair, from Dr. Schott's discussion, to conclude that observations by means of floats are likely to contribute valuable additions to our knowledge of the surface movements of the waters of the sea, when taken in conjunction with systematic observations by more precise methods, of which the distribution of temperature and salinity is probably the most satisfactory. Taken by themselves, the float observations are liable to be seriously misleading.

H. N. D.

\section{A COMPARATIVE STUDY OF VISUAL ACCOMMODATION.}

$\mathrm{SO}$ recently as five years ago but little was known with certainty regarding the refraction and accommodation in animals with "camera eyes." It is Beer's ${ }^{1}$ credit to have made an exhaustive investigation of a large number of animals with the aid of all modern ophthalmic methods, in addition to an experimental method of his own devising, namely, electrical stimulation of the enucleated eye.

No mechanism for accommodation is known in the facetted eyes of crabs and insects; according to Exner it is not required. The retina is comparatively thick, and moving an object from $80 \mathrm{~cm}$. to $\mathrm{I} \mathrm{mm}$. from the eye causes an alteration of but $O 1 \mathrm{~mm}$. in the position of the image.

A similar argument was supposed to hold good for the rabbit's eye, even by such a distinguished physiologist as Magendie; but this was due to an experimental error. Kepler, although ignorant of accommodation, recognised, nevertheless, that the image on the retina must be sharp for visual purposes.

Speaking generally, an eye must be able to accommodate proportionally to (I) its own size, (2) the width of the pupil, (3) the closeness of the retinal mosaic. Whilst, therefore, an emmetropic man can see plainly at $5 \mathrm{~m}$. without exercising his accommodation, those animals -and there are many - with much larger eyes must, for the same acuity of vision, already accommodate at that distance. On the other hand, it is not so important for large animals to have so near a "near-point" as small animals. Small animals, e.g. birds, have to see objects clearly even when quite close ; they require a large range of accommodation. Larger animals, except monkey and man, who bring things close to the eye with the hand, can get on with a "near-point" of $I-\frac{1}{2} \mathrm{~m}$., corresponding to a range of accommodation of $\mathrm{I}-2$ diopters ; this is so with the horse and ruminants.

Three modes of accommodation are possible : (I) alteration in the refractive power of the various media; (2) 1 "The Accommodation of the Eye in the Animal Kingdom." By Th. Beer,
Lecturer on Comparative Physiology in the University of Vienna. NO. I 536 , VOL. 59] alteration of the curvature of the refracting surfaces ; (3) alteration of the relative position of lens and retina. This first method, by which Grimm in 1785 sought to explain accommodation, has never been actually observed. The last was formerly a favourite theory. It was taken up by Kepler and by Scheiner. Many absurd reasons were given, and mechanical hypotheses constructed by various individuals to support this theory; nobody thought of examining the actual facts. In certain classes of animals, viz. cephalopoda, fishes, amphibia and reptiles, accommodation is effected by alteration of the distance between lens and retina. In man, however, as in all mammalia, also in birds, lizards and tortoises, this is brought about by alteration in the curvature of the lens.

It is also obvious that active accommodation may be for a near (positive) or for a far (negative) point, viz. the resting eye may be adjusted for distance or proximity respectively.

The dibranchiate cephalopoda are the only invertebrates in which accommodation has been observed; and, although they have "camera eyes," their type, as a whole, is far inferior to that of vertebrates. By retinoscopy it was determined that their eye is normally adjusted for the near-point. The extent of this normal myopia varies between two and (as an extreme limit) ten diopters. The mechanism of accommodation is as follows:-The bulb forms half of a rough ellipsoid. At the equator is a flat, strong cartilaginous ring, separating the anterior flattened portion of the eye from the posterior ellipsoidal part. Behind the ring the sclerotic is comparatively soft and yielding. In the anterior wall of the eye is also a strong muscular ring with radial fibres running from the cartilaginous ring to the ciliary body, which is firmly attached in the equatorial region of the lens. When this muscle contracts it pulls back the whole anterior wall of the eye, including the ciliary body and lens, towards the interior of the eye. The resulting increased pressure would tend to make the bulb of more spherical shape, with consequent increase of distance between lens and retina, but the thinner consistency of the posterior half leads to an actual diminution of the antero-posterior diameter, and consequent approximation of retina to lens. The iris, which lies practically outside the bulb, and also serves as lid, although extremely sensitive to light, takes no part in accommodation.

Teleostean fishes, although the structure of their eye bears a superficial resemblance to that of the cephalopod
eye by virtue of the spherical form of the lens, but is in other respects vertebrate in structure, are, nevertheless, myopic and accommodate for distance. The thickness of the retina, with its sensitive layer on the outer side (in the cephalopoda it is on the inner side), introduces a factor which has to be taken into account when estimating the refraction. Thus an apparently hypermetropic eye may prove to be really myopic. The comparative opacity of water, which does not allow of distinct vision for any great distance, accounts for their permanent myopia, but their range of accommodation is sufficient to enable fishes to focus parallel rays on the retina. But since their cornea is not, as was formerly supposed, flattened, when taken out of water they are so highly myopic that the correction which they possess would be of no value or account. The mechanism of the adjustment is different to that of the cephalopoda, and quite different to that of the vertebrata.

Ciliary body, ciliary muscle, zonula, spaces of Fontana do not exist in fish-eyes, and the iris does not glide on the lens, but is generally quite free. The spherical lens is suspended from above by a strong triangular band ; below is the structure known as the "companula," which, from its function, Beer re-names the "retractor lentis"; it draws back the lens nearer to the retina during accommodation. This can be seen on electrical stimulation of the recently enucleated bulb, even after removal of the cornea. 